DUO XU, Ph.D. Candidate ${ }^{1}$

E-mail: 516472407@qq.com

HUIJUN SUN, Ph.D. ${ }^{1}$

(Corresponding author)

E-mail: hjsun1@bjtu.edu.cn

${ }^{1}$ Key Laboratory of Transport Industry of Big Data

Application Technologies for Comprehensive Transport

Beijing Jiaotong University

No.3 Shangyuancun, Haidian District, Beijing P. R. China
Traffic Planning

Original Scientific Paper

Submitted: 22 Jan. 2020

Accepted: 26 June 2020

\title{
STUDY ON PROFITABLE SHARED PARKING MANAGEMENT BASED ON DAY-TO-DAY EVOLUTION MODEL
}

\begin{abstract}
Parking problems are getting increasingly serious in the urban area. However, the parking spots in the urban area are underutilized rather than really scarce. There is a large number of private spots in the residential areas that have the potential of being shared. Due to its private nature, shared parking is usually operated by a profitable mode. To study the utilization of shared parking and its impact on the morning commute, this paper proposes an evolution model. The supply side is a profit-chasing manager who decides on the selling prices and the business scale, while the demand side refers to travellers who respond to costs and choose the trip mode. By analysing the behaviour (strategy) of both sides, the study covers: 1 - the attraction and competition between parking lots and trip modes, 2 - the utilization and user composition of the parking lots. By inducing two numerical examples, the conclusions are that 1 - managers can achieve maximum profit and optimal allocation through price adjustment and quantity control; 2 - publicity (system cost minimization) and profitability (profit maximization) are consistent under certain threshold conditions; 3 - competition exists between parking lots as well as trip modes; some parking lots are even in short supply; profitable management does not create a market monopoly.
\end{abstract}

\section{KEYWORDS}

shared parking; parking permit; parking spot allocation; profitable management.

\section{INTRODUCTION}

The increasing demand for automobiles and limited public space lead to severe parking issues in modern cities. As the end of a trip, parking substantially impacts the travellers' behaviour, and parking management is normally considered as an integrated part of travel demand management which has been paid lots of attention by the transportation planners and government. Studies show that although there is only one hour on average that a vehicle is in motion daily, the other 23 hours being static, finding a parking spot and walking to work often constitute an appreciable fraction of the total travel time [1]. In America, the time cost that a vehicle looks for a vacant spot accounts for $30-50 \%$ of the total travel time $[2,3]$, and it pays the parking fee for more than $\$ 5$ on average, nearly $70 \%$ of the direct travel cost [4]. Shoup found that $30 \%$ of traffic jams in road networks are caused when people are cruising looking for parking spots, and about 8.1 minutes is spent on getting a vacant spot. Even if the cruising time is shorter, the cumulative consequences will be staggering, as there is always a large number of travelling cars in the metropolitan area [5]. In Chicago, cruising for parking produces a total of 63 million miles distance and 48,000 tons of carbon dioxide annually [6]. Similarly, cars cruise more than 366,000 miles a year in 15 blocks of Manhattan Upper West Side district; the distance is about 14 times around the Earth [7].

Similar to the shortage of road transport supply that leads to a slow traffic flow, the shortage of parking spots leads to the cruising flow searching for vacant parking spots. Fortunately, there is an essential difference between the problem of parking and road transport; parking supply in a city is often far from its limits. In addition to public spots, private spots occupy a considerable proportion of urban parking spots. The official data show the private spots in the city of Beijing and Hong Kong are respectively accounted for by $58 \%$ and $70 \%$ of total urban spots [ 8 , 9]. Shared parking has great potential to alleviate urban parking difficulties. 
From the perspective of parking management, over decades, as contradictions between parking supply and demand are not prominent, parking spots have been regarded as a free public resource during a long period until 1990s.

Parking management was first considered as an integrated part of travel demand management. Early academic literature mainly focused on the economic characteristics of parking, such as cruising for parking, spatial competition in the parking sector, temporal-spatial parking pricing, bottleneck model, dynamic pricing, minimum and maximum parking requirements [10]. They are more inclined to rely on price measures to adjust the excess demand and achieve a theoretical match between demand and supply. However, the equilibrium point is difficult to achieve as the "price - demand" relationship is hard to get accurately in practice, and the fluctuation in demand will also hinder the system from achieving the optimum.

In recent decades, parking management modes combined with information guidance have drawn more attention. From the initial traffic broadcast and variable message signs, to the current parking guidance system and parking reservation system based on monitoring the utilization of parking lots or spots. It has been proven that information plays an important role in further eliminating the parking uncertainty and improving the system efficiency $[11,12]$. Despite this, the system optimum is still difficult to achieve when the parking lot is nearly saturated. Some projects in practical filed adopt a sub-optimal strategy (slightly higher price than the equilibrium price) to keep a small number of spots vacant (e.g. $85 \%$ occupancy rate in SFpark as a compromise) to avoid excessive parking costs.

With the revolution of information and communication technology, the parking permit has received growing attention in the field of traffic demand management. It is a new management scheme integrating quantity control, price adjustment and information guidance. It originated in the field of environmental protection for the regulation of externalities in the 1960s [13, 14], then introduced to managing road transport in the 1990s and attracting more concerns now [15 23]. The main advantage is that the policymakers can design the initial allocation of permits to influence the actual distribution of users and easily achieve the system goals.
Different from public parking, shared parking spots are often private ones; both the supply side and the demand side are rational and sensitive to the benefits and costs. Therefore, shared parking has the characteristics of (1) parking prices (including rent and lease) change more frequently; (2) spots number and opening hours are more flexible (constrained by more factors); (3) trading platform and medium are required to release parking spot information and ensure transactions, etc. The parking permit is better to meet the above requirements. Theoretical research is mainly focused on shared parking spots purchasing, allocation, transaction and pricing mechanisms, etc. [24-29]. In the practical field, a few countries have preliminarily implemented private parking spots sharing. The users reserve and exchange parking rights by transaction medium such as permits or electronic parking tickets (e.g. Just park in London, RoverParking in Toronto, Spotpark in the United States, Parkhound and Circa Park in Australia).

As shared parking is still in the early stage, the current research mainly focuses on the micro-level, e.g. optimal allocation of parking permits, profitable management of single parking lot, parking permit trading mechanisms, etc. They mostly take a single parking lot as the research object, and seldom consider the impact on the travel group, such as the connection with other alternative parking lots, or other travel modes.

Based on the existing research, from the aspect of middle-level this paper studies the situation of multiple parking lots and multiple trip modes. (1) assume there are competitions between both, the shared parking lots and multiple trip modes; (2) on the basis of manager's profitable objective and parking permit (reserve and allocation) scheme, day-to-day evolution model is taken to describe the interaction process (manager formulates strategy, travellers response to it) between the manager and the traveller which may be a black box problem in reality (cannot be calculated by analytic method); (3) discuss the monopolistic issue of the shared parking (profitable) management and its similarities and differences with public parking management.

The remainder of this paper is organized as follows. Section 2 presents the basic components of the parking system, formulates the trip cost. Section 3 introduced the learning behaviour of travellers and the day-to-day evolution mechanism. Optimal allocation and period-to-period adaptive 
management are elaborated in Section 4. Then in Section 5, two numerical experiments are conducted to illustrate the dynamic model and analyse the utilization of the shared parking lots. Sections 6 and 7 discuss, conclude and give the prospect of the paper.

\section{BASIC COMPONENTS OF THE MODEL}

To simply express a shared parking model, the following settings are made: (1) Travellers (as the demand side) decide whether to choose a shared parking mode according to the trip cost they perceived. (2) Shared parking lots adopt the parking permit management scheme and the spots are traded by permits via an online platform. (3) Travellers apply spots once a day (for commuting); they must obtain the authorization (permit) from the manager before a trip. (4) A manager operates shared parking lots for profitable purposes (maximizing profit), they determine to buy the number, selling price and allocate permits to the travellers.

\subsection{Assumptions}

The parking of a certain business district (not unique) in the urban areas is studied. As shown in Figure 1, the business district is at the centre, the travellers reside around it. The circle boundary in the Figure is the research scope, e.g. the minimum circular area including all departure origins. The numbers outside the Figure represent the polar angles.

To facilitate the presentation of the essential ideas without loss of generality, the following basic assumptions are made.

A1. Network. Business district (Destination of travellers) is at $O$. There are $M$ shared parking lots (circles in Figure 1), and each lot has an equal distance from $O$. Their locations are represented by polar coordinates $\left(\rho, \varpi^{m}\right)$, and the number of available spots that can be used for shared parking is $K_{m}$.

Assumption 1 sets the locations of the shared parking lots, considering as follows. First, due to the attributes of land use, the residential area is geographically inferior to the public parking lots in commercial areas. Private parking spaces which can be used for shared parking take the majority of parking spaces in the cities. For example, there are 3.8 million parking spots in the urban area in Beijing, among them, 2.2 million are residential parking spots which account for more than $90 \%$ excluding public spaces. Therefore, they cannot be too close to
$O$. Second, multiple parking lots are available near the target point as there are generally more than 10 parking lots in a square kilometre in the central area of the city (e.g. in Beijing) and there are 15 parking lots on average per square kilometre in each central district [8]). Third, because car users prefer a short walking distance after parking (generally no more than $0.3 \mathrm{~km}-0.6 \mathrm{~km}$ or within one block [30]), their needs have to be within the travellers' acceptable distance and cannot be too far from $O$. The $K_{m}$ is the total spots number the manager can use in lot $m$ (the total number a manager can use is $\sum_{M} K_{m}$ ).

A2. Traveller. Travellers depart from $I$ origins (as asterisks shown in Figure 1) and have the same value of time. The location of origin $i$ is represented by the polar coordinate $\left(\rho_{i}, \omega_{i}\right)$ and satisfies $\rho_{i}^{>} \rho, \forall i$. For each origin, the total daily trip number $N(i)$ is fixed.

A3. Trip mode and share rate. Travellers have $L$ trip options including shared parking. Let $a$ be the shared parking mode. The share rate of each trip mode $S_{l}(i)$ is determined by its cost perceived by the travellers from origin $i$. Except for shared parking, it is assumed that the costs of other trip modes include two components which are distance-relevant cost $f_{l}(\rho)$ and distance-irrelevant cost $g_{l}$. The logit model is used to calculate the share rate. We denote $N_{l}(i)$ as the number of travellers who plan to choose mode $l$ from origin $i, D_{l}(i)$ be the number of travellers who actually choose mode $l$ from origin $i$ (due to capacity constraints and other reasons, not all travellers who plan to choose mode $i$ can actually be satisfied).

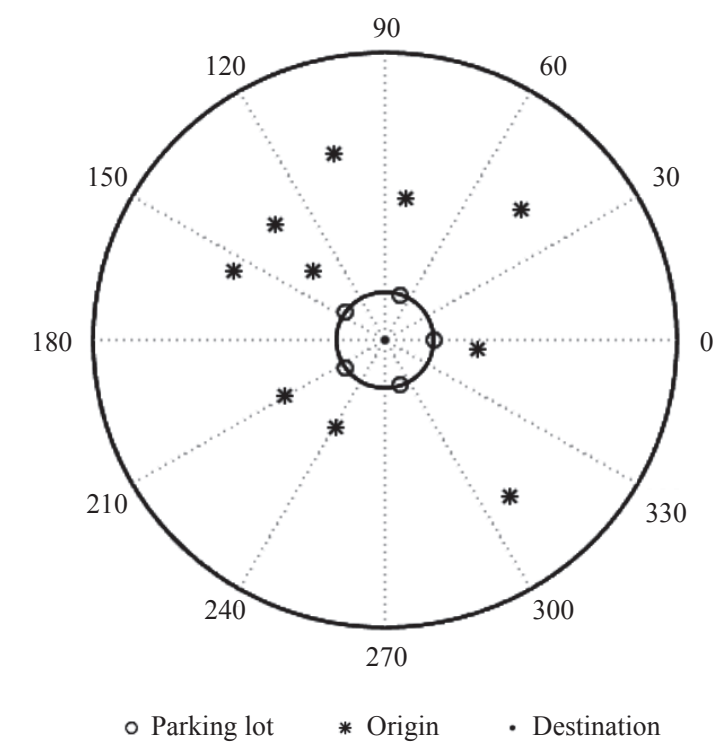

Figure 1 - Origins and parking facilities of a certain working zone 
A4. Parking area. The area $\left(A=\pi \rho_{1}^{2}\right)$ enclosed by shared parking lots is small and the traffic convenience inside is low (car-drivers first arrive in the area and travel along the surrounding road to the target lot.).

Assume 4 sets the route of the shared parking driver (they choose a parking lot within acceptable walking distance, generally no more than one block, as described above. Considering the fact that the road conditions inside most blocks are poor or unpassable, so the travellers first choose the peripheral secondary roads and branch roads). (1) Area $A$ is small compared to the entire city [8], travellers choose the same routes as they drive directly to $O$ before arriving at $A ;(2)$ Based on the Assumption 1 (the size of Area $A$ ), $A$ is often a block with low internal road grade or no public roads. As it is of less convenience, travellers do not travel through $A$ to save travel time.

A5. Travel speed of the shared parking mode. It is assumed that the trip is divided into three phases: the first is from origin $i$ to the boundary of area $A$, with the speed of constant car speed; the second travels around the boundary to parking lot $m$, the speed varies with the flow rate on that boundary; the third is between parking lot $m$ and destination $O$, with the speed of constant walking speed.

Assume 5 is the environmental setting of the shared parking mode. As there are many business districts in a city, it is assumed that the number of travellers to a certain district is far lower than the total traveller number in the city. The density of cars destined for $O$ is low when the travellers are far from $O$; car speed is mainly decided by external traffic; a constant speed is set for simplicity. The mutual influence gets stronger when the travellers are near $O$, car speed will decrease as more travellers drive on the surrounding roads of area $A$.

A6. Parking permit application and allocation. Travellers applying for a spot in a specific lot on the principle of minimum perceived cost. The manager allocates the parking permits (containing information) according to the applications of travellers before the trip. Not all applicants can definitely obtain a parking permit, but once they obtain it, they are not allowed to give it up.

\subsection{Trip cost}

According to A5, the trip cost of the traveller who will depart from $i$ through $m$ to $O$ is expressed as:
$C_{a}(i, m)=\alpha \cdot\left(\frac{\rho_{i}-\rho}{v_{a}}+\frac{\rho \cdot\left|\varpi_{m}-\omega_{i}\right|}{v_{a} \cdot \gamma\left(D_{a}\right)}+\frac{\rho}{v_{w}}\right)+p$

where $a$ represents the shared parking mode; $v_{a}$ is the car speed out of area $A ; v_{w}$ is the walking speed; $\left|\varpi_{m}-\omega_{i}\right|$ is the angle between origin $i$ and lot $m ; D_{a}$ is the actual total travel number around area $A$; and $\gamma(\cdot)$ is the decreasing function of $D_{a}$, which shows that the car speed around area $A$ is reduced by the flow; $\alpha$ is the value of time; $p$ is the parking price of lot $m$.

$D_{a}=\sum_{I} D_{a}(i)$, indicates that the actual total travel amount is the sum of the trips from all origins; $D_{a}(i) \leq N_{a}(i) \leq N(i)$ indicates that in origin $i$, the number of travellers who actually obtain a parking permit does not exceed the applicant number and the total trip number. $D_{a} \min \left\{\sum_{I} N_{a}(i), \sum_{M} K_{m}\right\}$, indicates the actual shared parking number is the smaller value between the applicants number and the available spots number.

According to $\mathrm{A} 3$, the general cost (from $i$ to $O$ ) of other trip modes is denoted as:

$C_{l}(i)=f_{l}\left(\rho_{i}\right)+g_{l}, \quad l \neq a$

where $l$ represents the trip mode other than $a ; f_{l}(\cdot)$ and $g_{l}$ are the distance-relevant and distance-irrelevant function of mode $l$, respectively.

\section{LEARNING BEHAVIOUR AND DAY-TO-DAY EVOLUTION}

In the day-to-day evolution model with a learning process, the travellers are assumed to make choices once a day. The calendar time is denoted $t$ and the time step is set $\Delta t=1$ as one day. For the parking lots manager, they adjust the strategy period to period, where a period should be long enough (e.g. 15 days or a month) to ensure all the travellers have adapted to the new strategy, and the manager can devise a strategy for the next period. The period is denoted by $T$ and it is supposed that day $t$ belongs to period T. Equation 1 is rewritten as:

$C_{a}^{t}(i, m)=\alpha \cdot\left(\frac{\rho_{1}-\rho}{v_{a}}+\frac{\rho \cdot\left|\varpi_{m}-\omega_{i}\right|}{v_{a} \cdot \gamma\left(D_{a}^{t}\right)}+\frac{\rho}{v_{w}}\right)+p_{m}^{T}$

Equation 2 can be rewritten as:

$C_{l}^{t}(i)=f_{l}^{t}\left(\rho_{i}\right)+g_{l}^{t}, \quad l \neq a$

\subsection{Learning behaviour}

Travellers are assumed to make choices based on their perceived costs. Their perceptions are daily updated based on both the past experiences and 
the experienced costs of the current day. Let $C_{p}^{p, t}(i)$ and $C_{l}^{e, t}(i)$ be the perceived cost and the experienced cost of trip mode $l(l \in L)$ from origin $i$ on day $t$, respectively. Then the perceived cost on day $t+1$ is determined as follows:

$C_{l}^{p, t+1}(i)=\tau \cdot C_{l}^{p, t}(i)+(1-\tau) \cdot C_{l}^{e, t}(i)+\varepsilon$

where, $0<\tau<1$ is a learning parameter associated with the perception and experience of the previous day; $\varepsilon$ is a stochastic item obeying the Gumbel distribution, indicating a cognitive error in the perceived cost.

The travellers decide whether to be an applicant according to the perceived costs $C_{a}^{p, t}(i)$. According to A2, the number of travellers who choose a specific mode $N_{l}^{t}(i)$ from origin $i$ on day $t$ is:

$N_{l}^{t}(i)=N(i) \cdot S_{l}\left[C_{l}^{p, t}(i)\right]$

According to $\mathrm{A} 3$, the share rate of mode $l$ is:

$S_{l}\left[C_{l}^{p, t}(i)\right]=\frac{\exp \left[-\theta \cdot C_{l}^{p, t}(i)\right]}{\sum_{L} \exp \left[-\theta \cdot C_{l}^{p, t}(i)\right]}$

where $\theta$ is a parameter.

Combining Equation 5 into Equation 6, the day-today dynamical system can be written in the following vector-matrix form:

$$
\begin{aligned}
& C^{p, t+1}=\tau \cdot C^{p, t}+(1-\tau) \cdot C^{e . t}+\varepsilon \\
& n^{t+1}=N \cdot S\left(C^{p, t+1}\right)
\end{aligned}
$$

where $C^{p}$ and $C^{e}$ are the perceived trip cost and experienced trip cost, respectively, $N$ is a diagonal matrix that has travel flow $N(i)$ as its diagonal elements. Since the experienced trip $\operatorname{cost} C^{e}$ is based on the real traffic flow $d$, Equations 8 and 9 can be rearranged as:

$$
\begin{aligned}
& C^{p, t+1}=\tau \cdot C^{p, t}+(1-\tau) \cdot C^{e}\left(d^{t}\right)+\varepsilon \\
& d^{t+1}=N \cdot A\left[S\left(C^{p, t+1}\right)\right]
\end{aligned}
$$

where $A(\cdot)$ is the reduction function from the planned trip number to the actual trip number (e.g. applying for a permit but not being allocated).

The traveller's perception will gradually press close to the actual travel cost. When the system gets into equilibrium, (1) $C^{p, t+1}-C^{p, t} \rightarrow 0$; (2) the demand is adjusted by cost and equilibrium is achieved with supply. The fixed point of the above system is derived:

$$
C^{p, *}=C^{e}\left[N \cdot S\left(C^{p, *}\right)\right]
$$

\subsection{Experienced cost and perceived cost}

When there is a difference between the supply and demand, a group of travellers from one identical origin who apply for shared parking may be allocated to more than one parking lot; some of them may even fail to get a parking spot. Let $D_{a}^{t}(i, m)$ be the number of travellers starting from $i$ and allocated to parking lot $m$ on day $t, C_{a}^{t}(i, m)$ be the car trip cost of the traveller's starting from $i$ and parking at lot $m$ on day $t, \sum_{M} D_{a}^{t}(i, m) \leq N_{a}^{t}(i)$; the experienced cost of mode $a$ is:

$C_{a}^{e, t}(i)=\sum_{M} \frac{D_{a}^{t}(i, m)}{\sum_{M} D_{a}^{t}(i, m)} \cdot C_{a}^{t}(i, m)$

Travellers from origin $i$ may be allocated to multiple parking lots. Equation 13 is the experienced cost including a weighted average of all situations.

According to Equation 5, the perceived cost is affected by the perceived cost and the experienced cost of the previous day. When $t=1$, it is assumed that the perceived trip cost $C_{a}^{p, 0}(i)=\min _{M} C_{a}^{1}(i, m)$, indicating that the shared parking traveller initially perceives the cost as the cost they park at the nearest lot.

Due to the fixed parking prices during a certain period $T$, the consistency of the traveller's response to costs will be reflected over time, and the perceived costs increasingly approach the actual costs.

\section{PROFITABLE MANAGEMENT OF SHARED PARKING}

Travellers choose the trip mode according to the cost which is affected by the strategy (mainly the price) set by the manager, and the manager adjusts the strategy (both purchase quantity and selling price) according to the net revenue each period. From the perspective of profit, the manager should: (1) reduce the number of redundant parking spots to avoid additional costs; (2) determine the proper price to make more revenue from the used parking spots.

\subsection{Optimal allocation mechanism}

First the allocation mechanism that matches the fixed travel demand and parking supply at the minimum cost is discussed. As Figure 1 shows, for any origin $i$ in the city, there is always one or several parking $\operatorname{lot}(\mathrm{s})$, the trip costs between $i$ and $O$ via it (them) is (are) minimized. The following definition is made: the collection of all locations (as origin) with minimum trip costs via parking lot $m$ to the destination $O$ is the spatial advantage area of lot $m$ ("advantage area" is used for simplicity). 


\section{Advantage area of parking lots}

The advantage area indicates that a parking lot has an advantage over all other parking lots in a certain area. It is the result of all parking lots competing against each other, including many factors (e.g. geography and price in this paper). If explored further, it will be seen that it is essentially a series of competitions between any two parking lots.

It is often believed that the advantage areas are arranged in the same order as parking lots because the geographical factor has the greatest influence. But this is not necessarily so in theory. For example, a parking lot with poor availability (such as its price is very expensive, or it is often quickly fully used); its advantage area may be contained within the advantage area of one parking lot rather than dividing the existing advantage areas.

Therefore, the formation process of advantage areas is described by using the method of reduction. Adding parking lots one by one and updating the boundaries of advantage areas.

Let $H_{m 1, m 2}^{t}$ be the angle of advantage area boundary between parking lot $m 1$ and $m 2$ counter clockwise on day $t$ (not necessarily adjacent). According to the definition, travellers depart from origin $i$, have the same trip cost either in lot $m 1$ or in lot $m 2$. Excluding the same cost before the travellers arriving at area $A$, the remaining costs are still the same.

$$
\frac{\alpha \rho \cdot\left(H_{m 1, m 2}^{t}-\varpi_{m 1}\right)}{v_{a} \cdot \gamma\left(D_{a}^{t}\right)}+p_{m 1}^{T}=\frac{\alpha \rho \cdot\left(\varpi_{m 2}-H_{m 1, m 2}^{t}\right)}{v_{a} \cdot \gamma\left(D_{a}^{t}\right)}+p_{m 2}^{T}
$$

Solve Equation 14,

$H_{m 1, m 2}^{t}=\frac{\omega_{m 1}+\omega_{m 2}}{2}-\frac{v_{a} \cdot \gamma\left(D_{a}^{t}\right) \cdot\left(p_{m 1}^{T}-p_{m 2}^{T}\right)}{2 \alpha \rho}$.

When two parking lots adopt the same parking price, $H_{m 1, m 2}^{t}$ is at the angle bisector of the two parking lots $\left(\varpi_{m 1}\right.$ and $\left.\varpi_{m 2}\right)$, and the order of advantage areas is the same as the parking lots, as shown in Figure 2. When a parking lot is charged a lower price, its advantage area will be larger, and vice versa. It may be reduced to zero (replaced by other lots) if it is charged too high.

For travellers, the competitive relationship between parking lots may not be important, their only concern is the intuitive perception of the result. However, for the manager, the formation of advantage areas is important. Since the supply and demand of each parking lot is heterogeneous, both the situation of supply shortage and surplus supply may occur. In many cases, the manager cannot complete the allocation in one round through the final result. When some lots are fully used and exit allo-

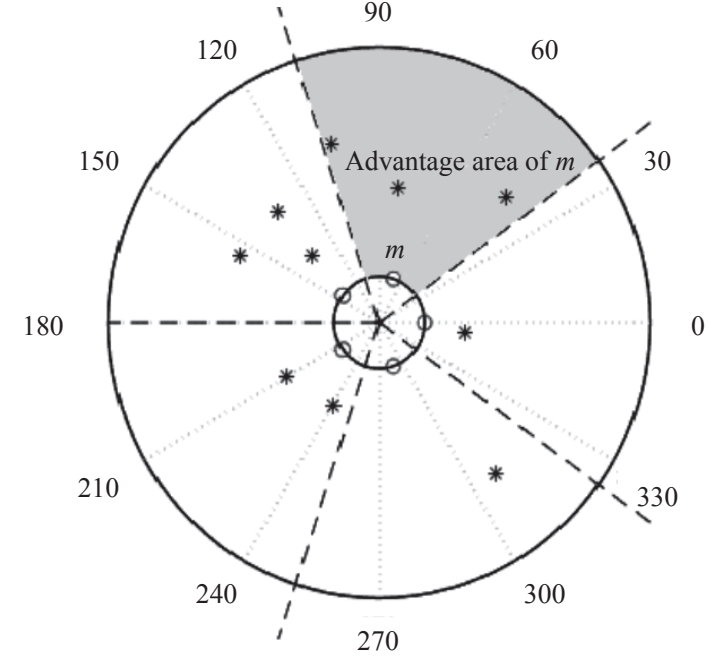

○ Parking lot * Origin - - Advantage area boudary

Figure 2-Advantage area division of shared parking lots

cation, the remaining lots re-divide the space, and the supply and demand will be re-matched again. To achieve optimal allocation, the manager needs to determine which parts of supply or demand are uneconomic. Therefore, to study this problem is the premise to explore the optimal parking allocation.

\section{Advantage area of trip modes}

Trip costs will directly affect the mode choice. According to Equations 4 and 7, the share rate of trip mode $l$ is determined by its cost, which is the sum of the distance-relevant items $f_{l}(\cdot)$ and distanceirrelevant items $g_{l}$. Derivate Equation 2 with distance $\frac{d C_{l}}{d \rho}=\dot{f}_{l}(\rho)$. The larger $f_{l}^{\prime}(\rho)$ is, the sharing rate of mode $l$ decreases as the distance increases.

In this paper, the distance-relevance of the shared parking trip mode $f_{a}(\cdot)$ can be approximately seen as $\frac{1}{v_{a}}$, because the speed is constant $v_{a}$ until arriving at area $A$. Therefore, for any feasible trip mode $l(l \in L, l \neq a)$, if there is $f_{l}(\rho)>\frac{1}{v_{a}}$, its advantage area is closer to destination $O$ than the shared parking, and vice versa.

\section{Optimal allocation}

The preceding texts illustrate the impact of the parking price on the changes of advantage area. The parking prices not only affect the boundary of the advantage area from the polar angle $\varpi$ (the higher the prices charged, the "narrower" the areas are, and vice versa), but they also affect the applicant number in the polar dimension $\rho$ (lose applicants to the competing modes). Based on this, the following conclusions are drawn: 
1) The manager can adjust the planned number of cars $N_{a}^{t}(i)$ and their parking location by adjusting the advantage area between both modes and parking lots by pricing.

Let $n_{m}^{t}$ be the demand (first choice) number in the advantage area $A_{m}$ on day $t$, then:

2) If the demand generated from area $A_{m}$ satisfies $n_{m}^{t} \leq K_{m}$, the optimal allocation mechanism is letting all $n_{m}^{t}$ travellers park in lot $m$.

3 ) If the demand generated from $A_{m}$ satisfies $n_{m}^{t}>K_{m}$, the optimal allocation is letting $K_{m}$ travellers who have smaller angle difference $\left|\omega_{i}-\varpi_{m}\right|$ park in lot $m$. (This part of the demand can be filtered out by pricing.)

From Conclusion 2 and Conclusion 3, the "multi-step allocation" can be defined: in each step, the manager only allocates the parking spots for the lots whose demand is greater than the supply, and for the remaining parking lots the advantage area is re-divided and the demand re-matched; when all the remaining parking lots with their demand are smaller than the supply, then allocate once.

4) When the demand for the shared parking travellers is fixed, the "multi-step allocation" has the lowest system cost.

Proof:

a) When the number of steps $S=1$ ( $\forall m \in M$, satisfy $n_{m}^{t} \leq K_{m}$ or $n_{m}^{t}>K_{m}$ )

It is easy to prove that all the parking lots are independent of each other; either the demands corresponding to each parking lot can be fully satisfied, or the supplies of all parking lots are insufficient. According to Conclusion 2 and Conclusion 3, the following is proven:

b) When the number of steps $S>1\left(\exists m_{1}, m_{2} \in M\right.$, $m_{1} \neq m_{2}$ while satisfying $n_{m 1}^{t} \leq K_{m}$ and $n_{m 2}^{t}>K_{m}$ )

The first $S$-1 step allocations are the cases where the demands are greater than the supplies. According to Conclusion 3, the demands remaining in each step are the ones with the largest parking cost.

Let $N_{a}^{t}=\sum_{I} N_{a}^{t}(i)$ be the total number of car trips on day $t$. If $N_{a}^{t}>\sum_{M} K_{m}$, that is, the remaining demands are greater than the remaining supplies in the $S$-th step, then the allocation is the same as the previous $S$-1 steps, and all the remaining $N_{a}^{t}-\sum_{M} K_{m}$, demands in $S$-th step are the ones with the largest parking cost; if $N_{a}^{t} \leq \sum_{M} K_{m}$, that is, the remaining parking demands can be satisfied by the remaining supplies in the $S$-th step. According to Conclusion 2, the remaining $\sum_{M} K_{m}-N_{a}^{t}$ supplies in the $S$-th step are the ones with the largest parking cost.

To conclude, the "multi-step allocation" achieves optimal matching between the demands and the supplies, and if there are demands (supplies) remaining, they are the most uneconomic demands (supplies).

\subsection{Profitable strategy}

In Section 4.1 the optimal allocation of the shared parking is discussed. For the manager, their goal is to maximize the profit by making strategy (without considering any social costs).

Denote the profit made by the manager as $P$. Then $d_{m}$ is the parking number at lot $m, c$ is the unit purchase cost of a parking spot.

Omit period $T$, the objective function is:

$\max P=\sum_{M}\left(d_{m} \cdot p_{m}-k_{m} \cdot c\right)$

s.t. $p_{m} \geq c, d_{m} \leq k_{m} \leq K_{m}$

The first term on the right side of Objective function 15 is the income part while the second is the cost part. Both the price and the purchased number are variables decided by the manager.

Function 15 can be rewritten as 16 according to the actual use of the parking spots:

$\max P=\sum_{M}\left[d_{m} \cdot\left(p_{m}-c\right)-\left(k_{m}-d_{m}\right) \cdot c\right]$

The first term on the right side of Objective function 16 is the income from the actually used spots, and the second term is the cost of the unused parking spot. Function 16 reflects the dual objectives of the manager, first, to obtain more income in the used parking spots, and second, to reduce the purchasing quantity of redundant parking spots.

In this process, if the purchasing quantity $k_{m}$ is relaxed to make it no less than the actual usage amount $d_{m}$, the two-variable optimization problem of Function 16 can be transformed into two independent single variable optimization problems. In other words, the manager only needs to pay attention to the income part and the cost part, respectively, in order to get the maximum profit.

\section{Optimal charge}

In the first stage, the pricing is discussed. Let $R$ be the revenue from parking lot $m$, then:

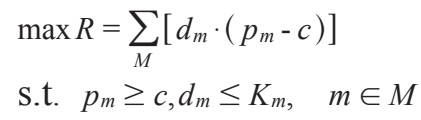


where, $R$ exists maximum value as demand $d_{m}$ has a reverse relationship with price $p_{m}$. When the marginal income equals the marginal cost, $R$ gets the maximum value. If $R$ keeps increasing as the price $p_{m}$ continuously changes in one direction, the optimal charge is in that direction change; otherwise, the optimal charge is in the opposite direction of that change.

The variable step method is used to obtain the optimal prices for each parking lot. Parking price in the current period is the sum of parking price and price change step in the previous period $p_{m}^{T+1}=p_{m}^{T+\Delta p_{m}^{T}}$. The price change step evolves over time and is determined by revenue changes. The price adjustment mechanism is:

Step 0: Initialize parking prices $p_{m p}^{0}$ price change step $\Delta p_{m}^{0}$ and convergence factor $\delta$;

Step 1: Calculate revenue $R_{m}^{1}$ of each lot when $T=1$, update price $p_{m}^{1}=p_{m}^{0+\Delta p_{m}^{0}}$, price change step $\Delta p_{m}^{1}=\Delta p_{m}^{0}$.

Step 2: Calculate revenue $R_{m}^{2}$ and compare it with $R_{m}^{1}$. If it increases, the price change is the same as the previous stage, $\Delta p_{m}^{2}=\Delta p_{m}^{1}$, otherwise $\Delta p_{m}^{2}=-\Delta p_{m}^{1}$; Step 3: Calculate revenue $R_{m}^{T}$ when $T>2$ and compare it with revenue $R_{m}^{T-1}$ of the previous period. If it increases, the price change is the same as the previous stage, $\Delta p_{m}^{T}=\Delta p_{m}^{T-1}$, if it decreases, reverse the price change direction and reduce the step length,

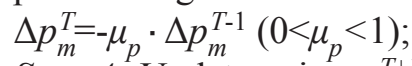

Step 4: Update price $p_{m}^{T+1}$, determine whether the price change step $\Delta p_{m}^{T}$ is smaller than the convergence factor $\delta$. If yes, end, otherwise return to Step 3.

The revenue of each lot in Steps 1 to 3 is:

$R_{m}^{T}=p_{m}^{T} \cdot \tilde{d}_{m}^{T}$

where $\tilde{d}_{m}^{T}$ is the estimated value of the actual parking quantity of lot $d_{m}^{T}$ in period $T$; (e.g. the parking number in the last few days of a period when the system is nearly stable).

The evolution of price adjustment in Step 2 and Step 3 is expressed as:

$\Delta p_{m}^{T+1}=\operatorname{Sgn}\left(R_{m}^{T+1}-R_{m}^{T}\right) \cdot \Delta p_{m}^{T}, \quad T=1$

$\Delta p_{m}^{T+1}=\left\{\begin{array}{cc}\Delta p_{m}^{T} & R_{m}^{T+1}-R_{m}^{T} \geq 0 \\ -\mu_{p} \cdot \Delta p_{m}^{T+1} R_{m}^{T+1}-R_{m}^{T}<0\end{array} \quad \quad T \geq 2\right.$

$\mu_{p}\left(0<\mu_{p}<1\right)$ is a parameter. $\operatorname{Sgn}(\cdot)$ is sign function, and it is $\operatorname{set} \operatorname{Sgn}(0)=1$.

For different period $T$, the adjustment of the price change step is different on the condition of $R_{m}^{T+1}<R_{m}^{T}$, as shown in Equations 19 and 20. When $\mathrm{T} \geq 2$, it can be inferred that the price exceeds the optimal value after the process of continuously approaching the optimal value. Reversing the symbol and narrowing the range will help in reaching the optimal charge price. However, when $T=1$, the above inference does not hold. There is high probability that the first price adjustment is in the opposite direction (unless the optimal price is somewhere between two prices and is closer to the initial one). A smaller step will slow the price evolution.

\section{Optimal purchasing number}

Since the price-setting mechanism in the preceding texts makes $p_{m}^{T}$ and $\tilde{d}_{m}^{T}$ converge to $p_{m}^{*}$ and $d_{m}^{*}$ respectively, the amplitude of the price change and demand change decreases as $T$ increases. In other words, the maximum (or minimum) value in one period is higher (or lower) than they are in some periods later. We have set $k_{m}^{T}$ as the relaxed value of parking spots purchased number, let $k_{m}^{T}$ be the maximum value of the actual parking number in former $K$ periods ( $K T$ days), $k_{m}^{T}=\max _{0 \leq j \leq K-1}\left\{d_{m}^{\tilde{T}_{-j}}\right\}$ satisfies $(j$ is an integer). $k_{m}^{T}$ approaches $d_{m}^{T}$ and $d_{m}^{*}$ as the system gradually approaches equilibrium.

\section{NUMERICAL EXAMPLES}

In this Section, we use two numerical examples to further illustrate: first, the evolution process including strategy formulation and travellers' response under different supply - demand level. Second, the impact of the shared parking lots on travellers' trip mode choices within the urban space.

It should be noted that shared parking is often considered as the supplement to alleviate the shortage of public parking facilities. Both of them mainly take cars as transportation tools, with small differences in the major cost items in the travel costs. Therefore, the competitive relationship between the two is no longer studied. In contrast, public transportation and cars have a strong mutual substitution in urban trips (either travel distance or cost), and it has the characteristics of stable travel time (mainly affected by distance) and less impact on the demand (large traffic volume). Therefore, in this section, we take public transportation as the only alternative trip mode (benchmark) and generate shared parking demand through the Logit model.

We mainly take parking prices, purchasing numbers, occupancy rates into consideration in Example 1 , the attraction at different distances, competition between parking lots and two modes in Example 2. It is set that the manager adjusts the parking price 
and purchasing number in each period according to Section 4. The perception updating and travellers' response to cost are based on Section 3 .

\subsection{Utilization of shared parking}

First, the utilization of parking lots is studied. In this section, it is assumed that all parking lots adopt the same price and the following parameters are set: Parking lots. It is assumed that the number of parking lots $M$ is $2,0.5 \mathrm{~km}$ away from destination $O$, their locations are $(0.5,0)$ and $(0.5, \pi)$, respectively, and the available parking number of two lots are $K_{1}$ and $K_{2}$ (different values in different cases), the buying price $c$ is 0 yuan for simplicity reasons.

Origins. There are two origins $(I=2)$ with locations $N(1)=\left(\rho_{1}, 0.25 \pi\right)$ and $N(2)=\left(\rho_{2}, 0.25 \pi\right)$. The travellers depart from $I_{1}$ and $I_{2}$ each day. $N(1), N(2)$ and $\rho_{1}, \rho_{2}$ are different values in different cases.

Travellers. Car speed $v_{a}$ is set and the walking speed $v_{w}$ is $30 \mathrm{~km} / \mathrm{h}$ and $6 \mathrm{~km} / \mathrm{h}$, respectively. The traveller's value of time $\alpha$ is 30 yuan per hour.

Demand function. The demand of two modes through the Logit model is generated and it is assumed that the developed public transportation can go directly to the destination from any origin without crowding and transfer. The average speed is $0.5 v_{a}$, the departure interval is 10 minutes. Then the cost is $C_{b}^{p, t}(i)=\frac{15 \rho_{i}}{v_{a}}+2.5$.

Congestion effect. It is assumed that the shared parking travellers are from all directions, thus the traffic flow near destination $O$ is uniformly distributed. The BPR function is used to depict the congestion effect, $\gamma\left(D_{a}\right)^{-1}=1+0.15\left(\frac{D_{a}}{C}\right)^{4}$, where the road capacity $C$ is set to 1,000 vehicles/hour.

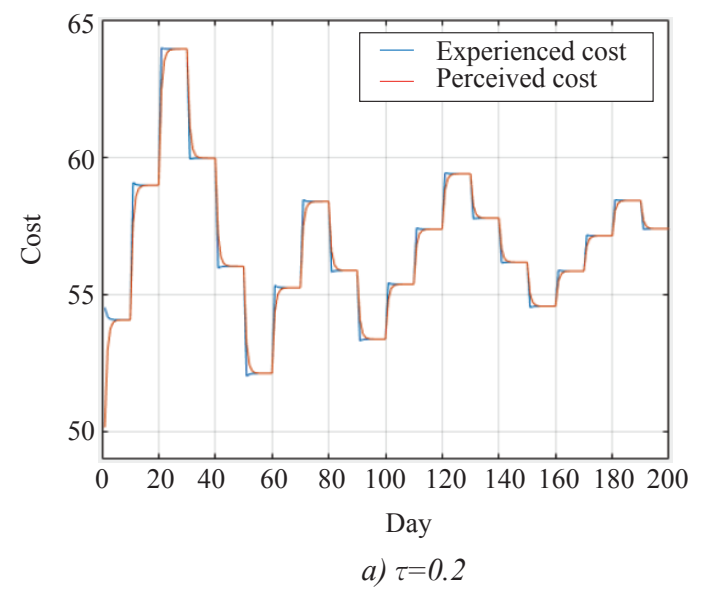

Period. The time set for the manager to adjust the strategy $T$ is 10 days. All parking prices and available spots are fixed in one period.

Initial parameters. Let the initial price step $\Delta p^{0}$ be 5 yuan, $\mu_{p}$ is 0.8 , and the convergence factor $\delta$ is 0 (we first observe the whole image).

Case 1-1: Observing the convergence of the system and the effects of learning parameters in day-to-day evolution

First, we start with a general scenario, two origins and two parking lots are spatially symmetric, and each lot has sufficient parking spots, the parking prices are the same. $\rho_{1}=\rho_{2}=30, K_{1}=N(1)=1,000$, $K_{2}=N(2)=1,000$

Figure 3 shows the relationship between the actual cost and the perceived cost in the first 20 periods in different $\tau$ value. When $\tau$ is small, the travellers pay more attention to the actual cost, and the perceived cost inclines to the actual cost rapidly after the manager changes the strategy. On the contrary, the travellers pay more attention to their own experience of cost, and it takes longer for the perceived cost to converge to the actual cost in a period.

Figure 4 shows the evolution of different $\tau(0.2$, $0.5,0.8)$. It can be seen from the Figure that different $\tau$ do not affect the convergence speed and result.

Figure 5 shows the convergence process of the purchasing number. The upper solid blue line is the actual purchasing number, while the lower solid orange line is the actually used number. In this example, the purchasing number is set equal to the maximum number in the former five stages $(j=5$ in the algorithm in Section 4.2). The initial value is $K_{1}$ (the manager purchases all spots in the first 30 days). As can be seen, both the number of actually used spots and the number of purchased spots gradually

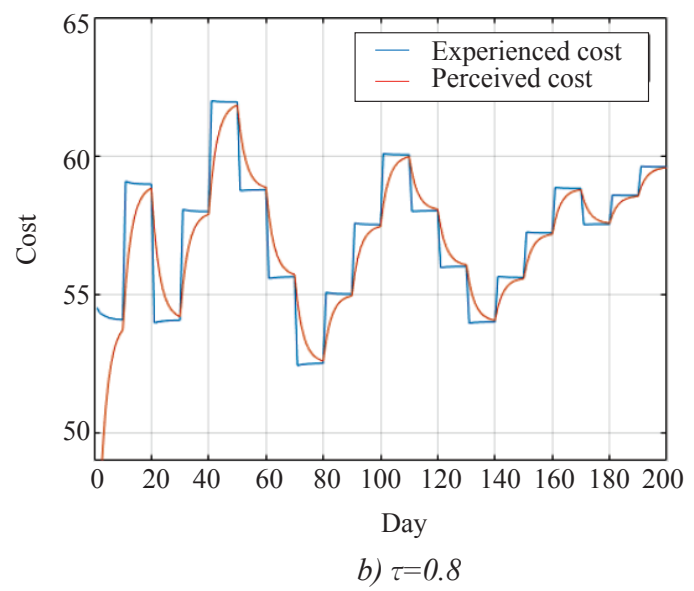

Figure 3 - Perceptual and actual cost 

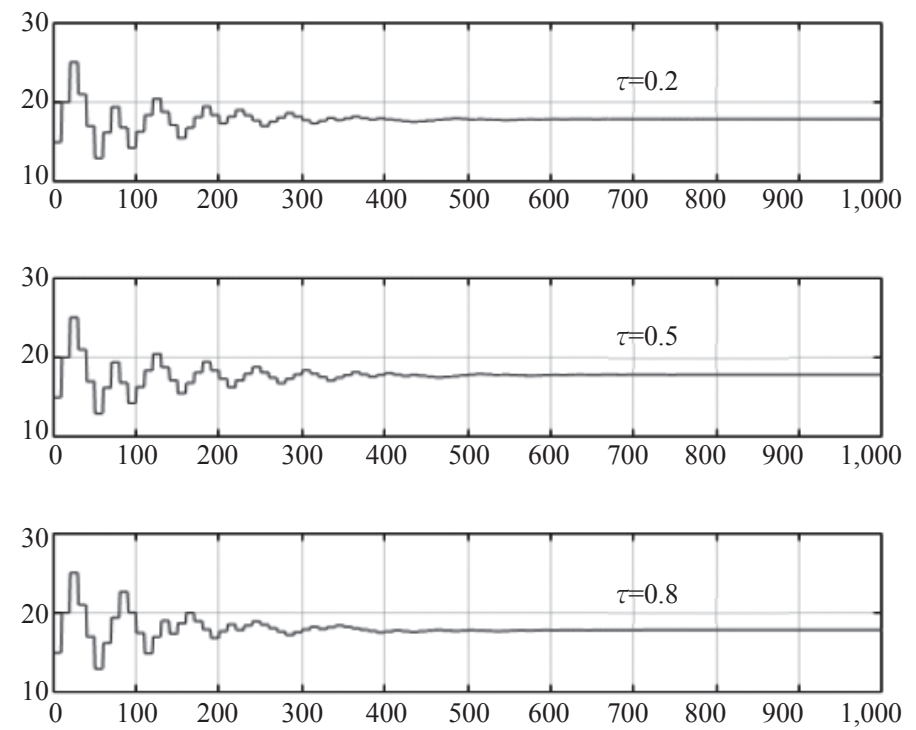

Figure 4-Evolution process with different $\tau$

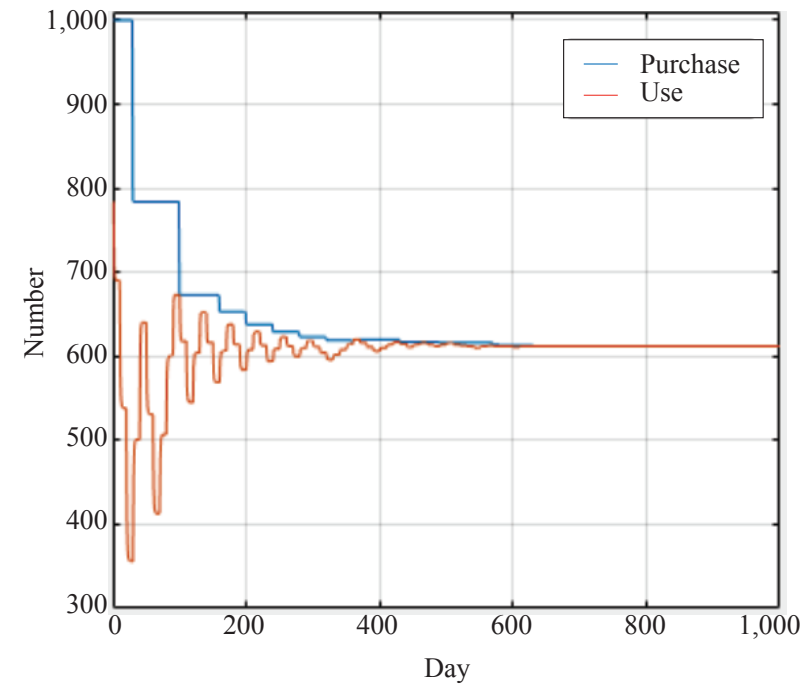

Figure 5 - Purchase and actual use number

converge to a certain value, and the purchased number keeps no less than the actually used number during this process.

\section{Case 1-2: Evolution process with different} parking lots capacity

Based on the previous case, the parking capacities $K_{1}$ and $K_{2}$ are adjusted $(1,000,650$, and 600 , respectively).

Figure $6 a$ shows when the parking spots are absolutely sufficient, and the profitable mode does not make full use of all parking spots. The actual parking number is 615 , parking prices are 17.88 yuan each lot, and the revenue (also profit) is 22,000 yuan. Figure $6 b$ shows when the available parking spots are reduced to 650 (but more than 615) each lot, the travellers also use 615 parking spots. Parking prices and the revenue keep still. Figure $6 c$ shows when the available parking spots are reduced to 600 (less than 615), travellers use all the 600 parking spots each lot, and parking prices then increase to 18.31 yuan, and the revenue decreases to 21,970 yuan.

Through Case 1-2, the conclusion is drawn that the actual utilized number of the parking lot in the profitable mode does not depend entirely on whether the parking spots are sufficient, but there is a threshold and when the parking capacity is under the threshold, the parking lots can be fully used; conversely, the additional parking spots (above the threshold) will not be used.

\section{Case 1-3: Threshold in different parking lot capacities}

Based on the previous case, we adjust the locations of two origins $\rho_{1}$ and $\rho_{2}$ to $20 \mathrm{~km}, 30 \mathrm{~km}$ and 50 $\mathrm{km}$, respectively, and $K_{1}, K_{2}$ ranging from 1-1,000.

In Figure 7, the red, blue and black solid lines represent the origins at $20 \mathrm{~km}, 30 \mathrm{~km}$, and $50 \mathrm{~km}$, respectively. In accordance with the case of $30 \mathrm{~km}$ in Case 1-2, there are also maximum number of parking spots (thresholds) for different scenarios, (434 at 20 $\mathrm{km}$ and 790 at $50 \mathrm{~km})$. According to the conclusion in Section 4.1, the proportion of mode $a$ increases as the trip length increases.

In line with the conclusion in Case 1-2, when the total parking number exceeds the threshold, the parking spots are redundant (as shown by the right horizontal portion of each curve). In our assumptions, the trip cost of mode $a$ is lower than the public transportation even if there are some congestions, so making full use of parking spots can reduce the system cost. 

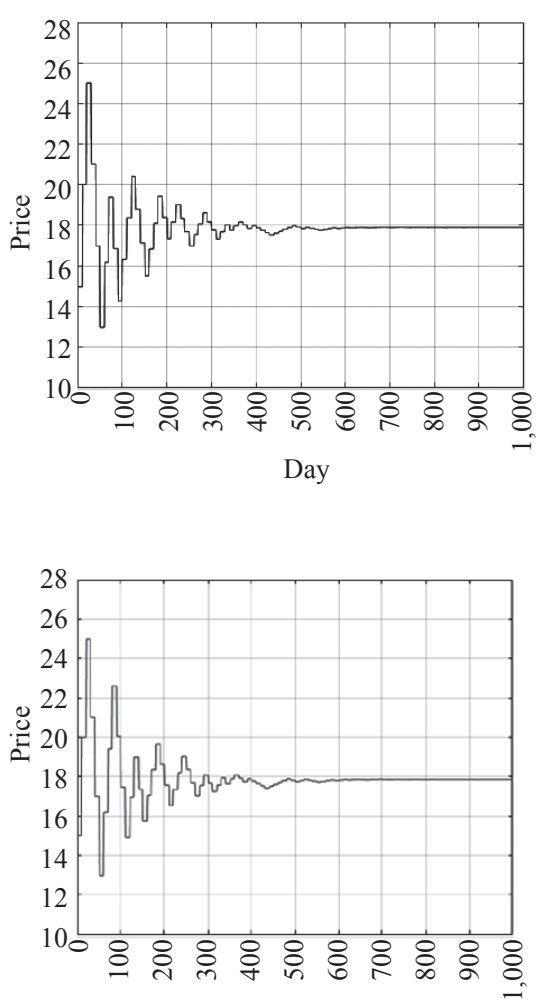

Day

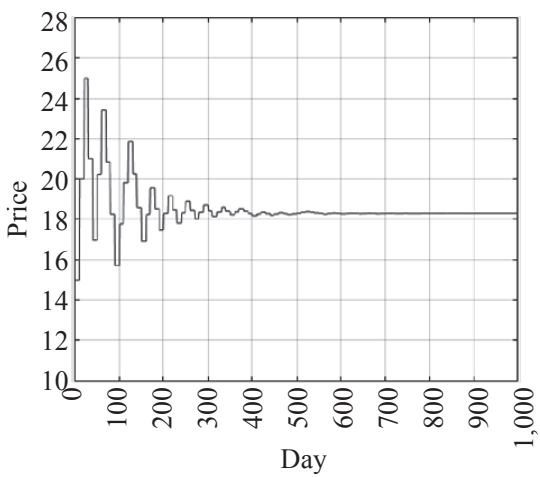

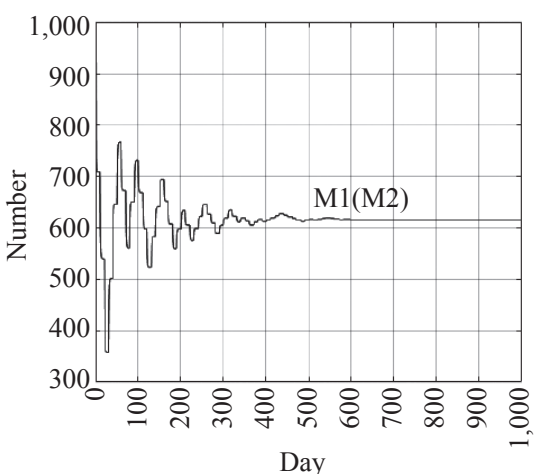

a) $K=1,000$

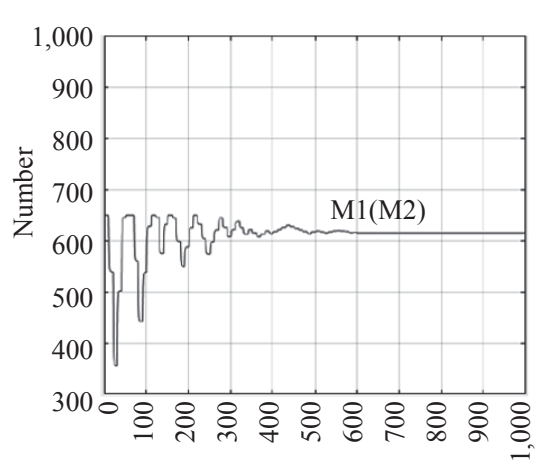

b) $K=650$
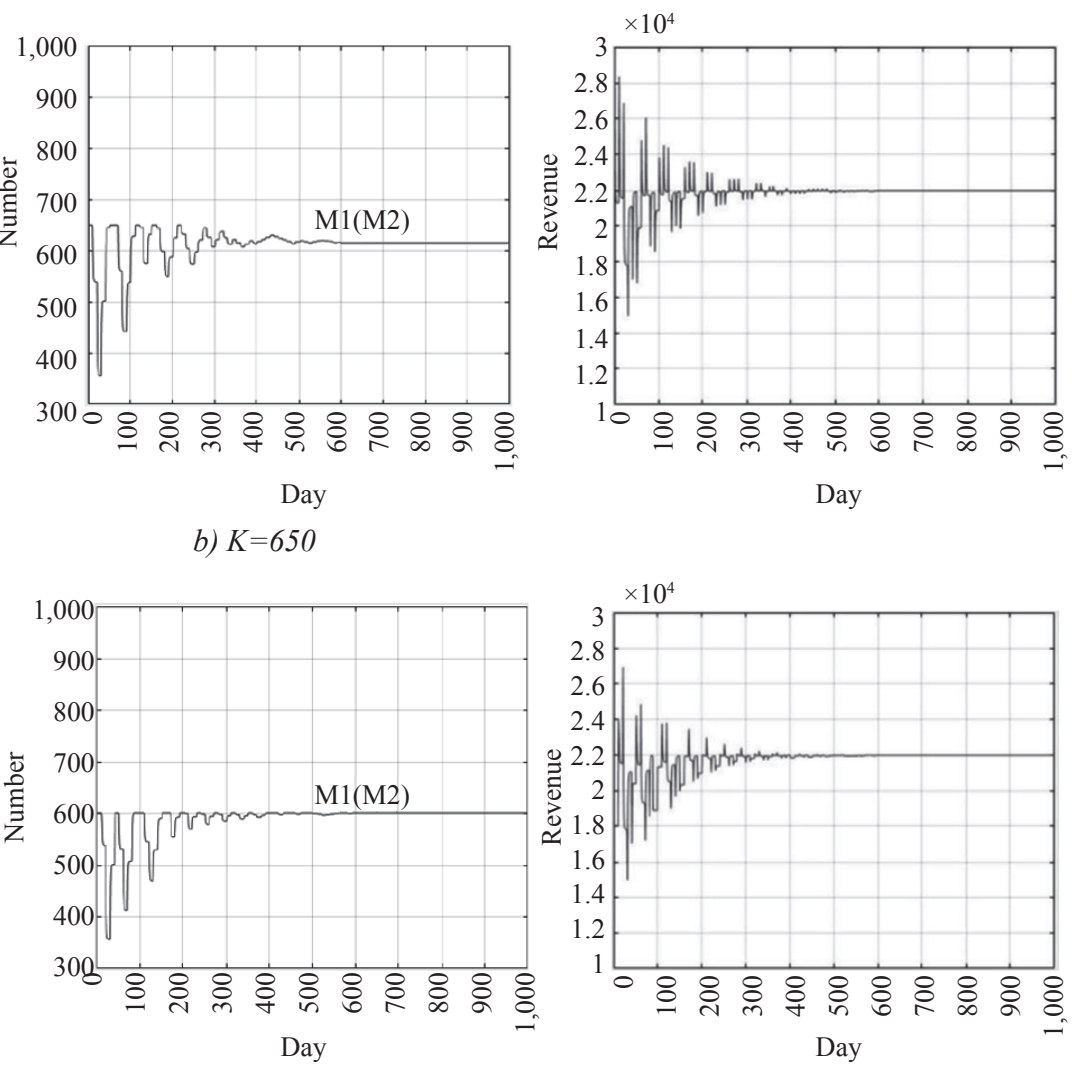

Day

c) $K=600$

Figure 6-Evolution process with different parking lot capacities

But in a profitable strategy, some spots are wasted. Therefore, the gap between the profitable mode and the public mode is separated when the number of parking spots exceeds the threshold.

Conversely, when the available parking spots are below the threshold, the profitable model can use all the existing spots (the diagonal line on the left side of each Figure). This conclusion shows that when the parking spot is below a certain amount, the profitable model makes full use of all parking resources. Therefore, when the parking spot is under the threshold, the profitable mode is equivalent to the public mode.

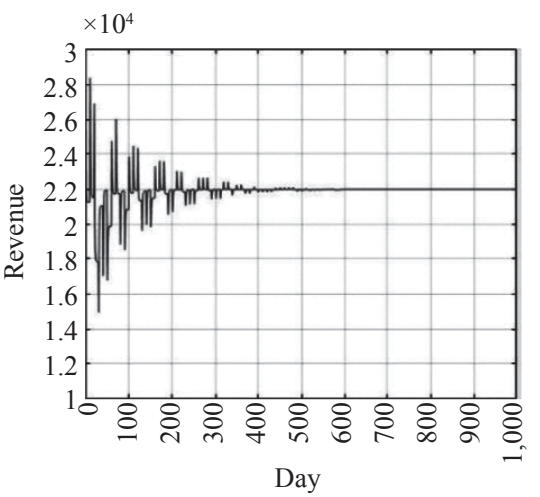

Case 1-4: Evolution process with heterogeneous origins

Set two origins $\rho_{1}=20 \mathrm{~km}, \rho_{2}=50 \mathrm{~km} . K_{1}$ and $K_{2}$ take $1,000,700,300$, respectively.

In Figure 8, the blue and yellow solid lines indicate the parking occupancy of Lot 1 and Lot 2, while the red and black dotted lines are parking numbers in Lot 1 from Origin 1 and Origin 2, respectively. We can see the blue and yellow lines from three figures, due to the same price adopted by two lots, the shared parking travellers from the near origin (I1) are significantly more reduced than they are from the far origin (I2). 


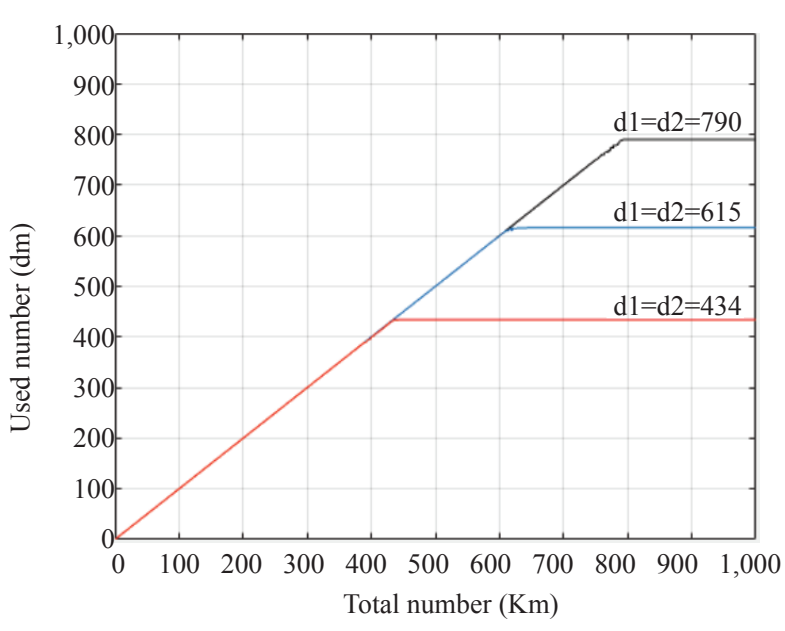

Figure 7 - Utilization under different available spots

Figure $8 a$ reflects the occupancy of the two lots when the spots are sufficient (can meet all car travel needs), Lot 1 is 48 , and Lot 2 is 822 . It indicates

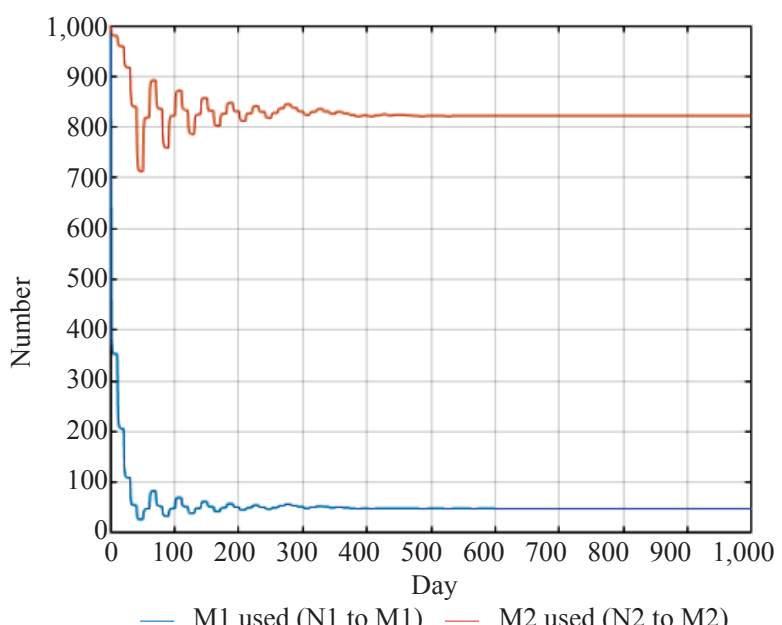

a) $K=1,000$ the profitable mode mainly getting the revenue from farther travellers by increasing the price and reducing the purchasing quantity.

As Figure $8 b$ shows, when the available spots number is medium (cannot meet all car travel needs), the travellers from farther origin begin to accept the lot with a higher cost (e.g. I2 to M1). The occupancy of Lot 1 is 141, in which 47 are from Origin 1 (red dotted line), and 94 are from Origin 2 (black dotted line). Lot 2 is fully used (700), and all are from origin 2 .

When the available spots are scarce, as Figure $8 c$ shows, all the lots are fully used. Occupancy of Lot 1 is 299 , in which 25 are from Origin 1 (red dotted line), 274 are from Origin 2 (black dotted line). Lot 2 is fully used (300), and all are from Origin 2. Compared with Figure $8 b$, the travellers from Origin 2 occupied more spots.

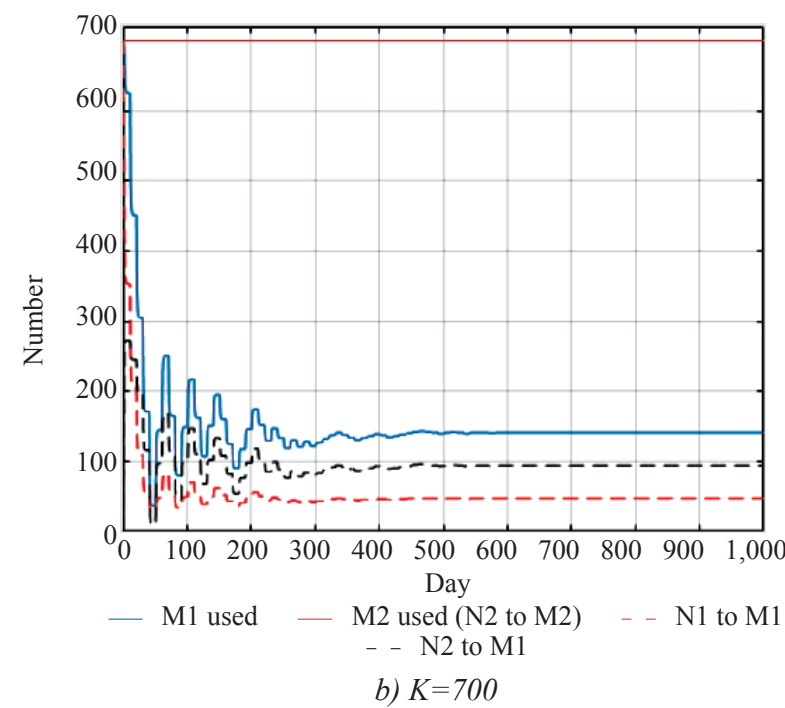

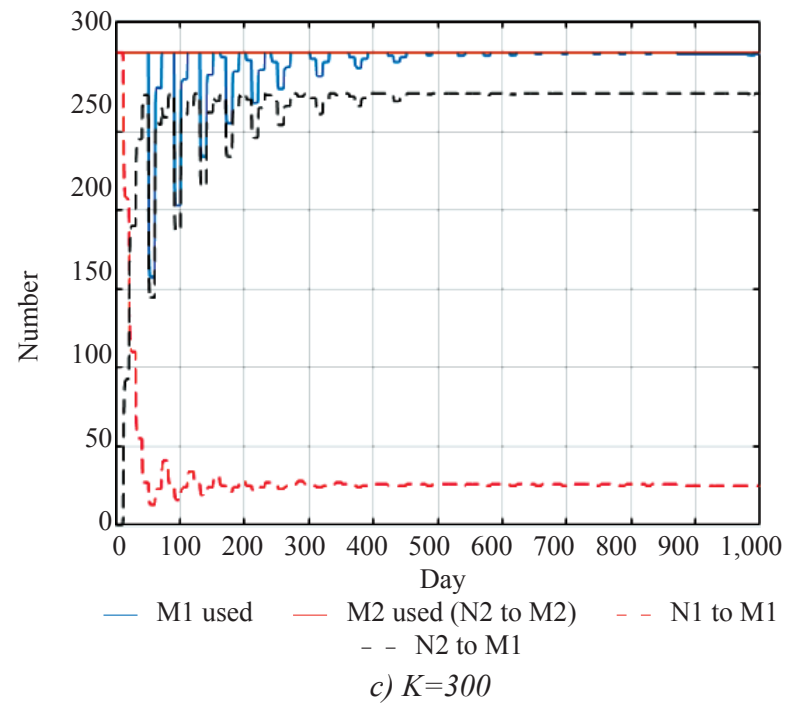

Figure 8-Occupancy of M1 and M2 
In line with Section 4.1, cases 1-2 and 1-3, firstly, the travellers departing from different locations have different sensitivities to the price charges. Compared with public transportation mode, longtrip travellers are more willing to choose mode $a$ than short-trip travellers when the trip cost increased. Secondly, although there is more waste in this case (heterogeneous origins with the same price), with the decreasing scale of parking lots, the profitable mode is getting closer to the public mode.

\subsection{Spatial coverage of shared parking lots}

After exploring the utility of shared parking lots in different scenarios, in this section, we continue studying the spatial impact of shared parking lots. Some parameter settings are reset:

Parking lots. It is assumed that there are three parking lots $(M=3)$; their locations are $(0.5, \pi / 2)$, $(0.5,7 \pi / 6)$ and $(0.5,11 \pi / 6)$; the number of available parking spots is $K_{1}, K_{2}$ and $K_{3}$, respectively (different values in different cases); the purchased cost is 5 yuan.

Origins. 180 origins $(I=180)$ are set and divided into five groups; each group contains 36 origins with a spot of $10^{\circ}$. Five groups are $5 \mathrm{~km}, 10 \mathrm{~km}, 15 \mathrm{~km}, 20$ $\mathrm{km}$, and $25 \mathrm{~km}$, respectively, away from the area in which parking lots are located, as shown in Figure 9. The circles in the centre indicate the parking lots while dots indicate the origins.

\section{Case 1-5: Spatial impact of homogeneous parking} lots in different supply and demand relation

Polar coordinates are applied to show the mode choice of different groups, where the polar angle represents the angle of origin and the polar axis

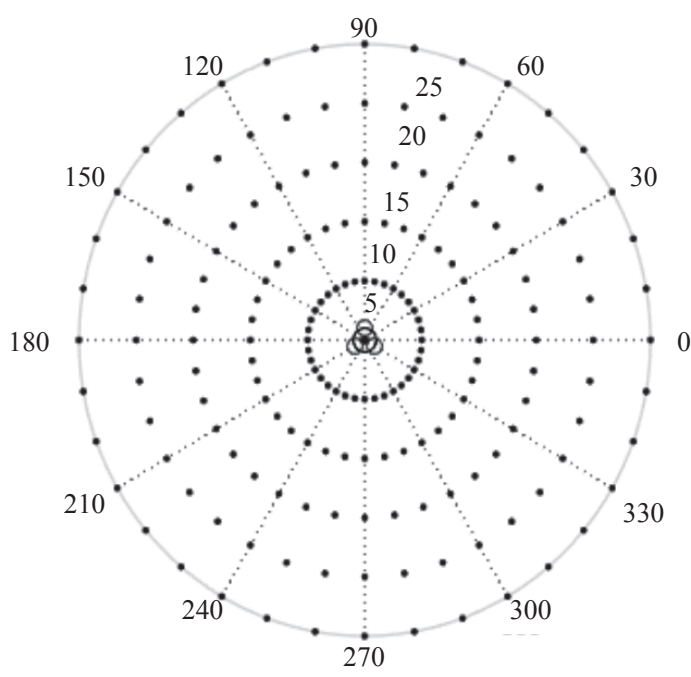

Figure 9 -Distribution of parking lots and origins (ranges from 0 to 1) represents the proportion of car travel. Five closed curves (green, purple, yellow, orange and blue) in Figure 10 correspond to five groups $(5 \mathrm{~km}, 10 \mathrm{~km}, 15 \mathrm{~km}, 20 \mathrm{~km}$, and $25 \mathrm{~km}$ ), which are fitted with the discrete data of 36 origins, and the black dotted line indicates the boundary of the advantage area.

Figure 10 shows the cases in which the capacity of all the parking lots $K_{1}, K_{2}$ and $K_{3}$ are equal to 1,200 , 615 and 200, respectively.

Figure 10a is the same as Figure 10b; even the available parking spots are sufficient, indicating in the process the available spots reduced from 1,000 to 615 , and the proportion of car trip in each group does not change. Figure 10c shows the different travel status when the number of available spots is 200 for each lot. As the cases are shown in Section 5.1, the parking threshold also exists (in this case it is 615 for each lot, occupancy rate is $51.26 \%$ ). When the available spaces are fewer than 615 , all parking lots will be fully utilized, and correspondingly, the parking fees increase from 20.2 yuan to 39.0 yuan.

By observing the above three figures, the following conclusions can be made:

First, the proportion of car trips is positively correlated with the trip length. The shorter the trip length the lower the proportion (the shorter the polar axis). From Figure 10a, the proportion of car trips in the $5 \mathrm{~km}$ group is between $5.1 \%$ and $5.9 \%$, and they increase to $95.2 \%$ and $95.8 \%$ in the $25 \mathrm{~km}$ group. It shows the competitive relationship between the shared parking and public transportation, the farther the origin is, the more advantageous the shared parking is, which is consistent with the conclusion in 4.1 .

Second, the proportion of car trips in each group decreases as the available spots are scarce and the parking prices increase; in addition, the decreasing amplitude gets larger as the trip length gets shorter; the proportion of car trips in $5 \mathrm{~km}$ group decreases from $5.5 \%$ (mean) to $0.3 \%$ (mean), decreased by $94.5 \%$; by contrast, the proportion in $25 \mathrm{~km}$ group decreases from $95.5 \%$ (mean) to $56.0 \%$ (mean), decreasing by $40.7 \%$, which means the price change impacts more the travellers near the city centre.

Third, when the parking lots adopt the same price, their impacts on the entire city are equal, and the boundary of the advantage area is exactly at the angle bisector. 
Fourth, for the origins in a specific group, car trip proportions are large when the angle between the corresponding lot is small. As shown in Figure 10, the curves are convex when the origins are close to the lot, and they are concave when the origins are close to the lot boundary.

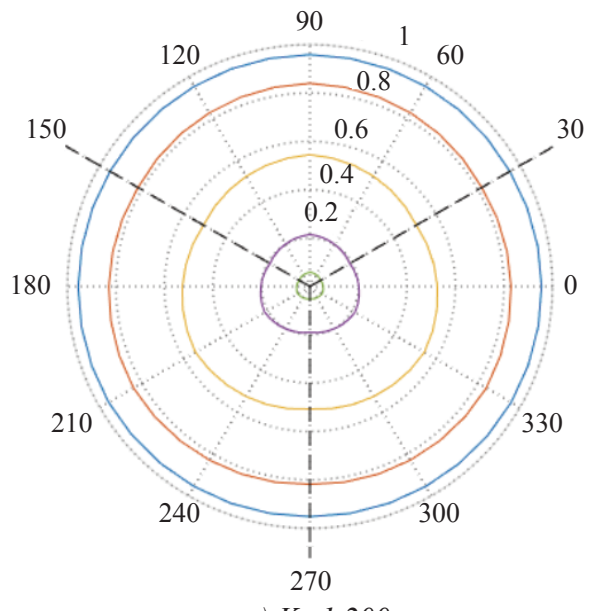

a) $K=1,200$

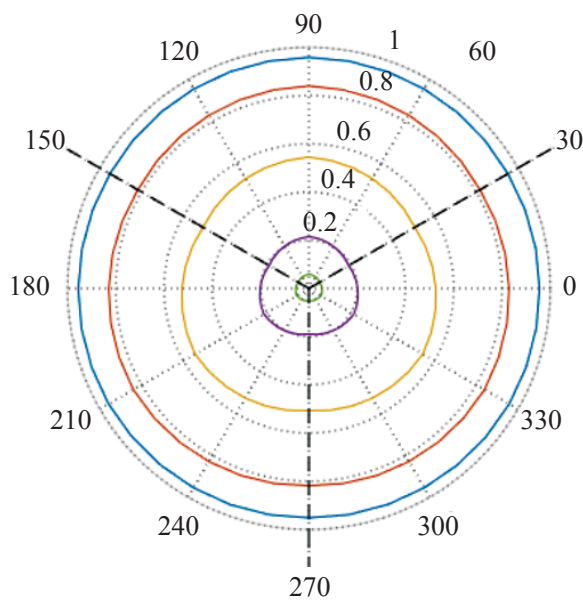

b) $K=600$

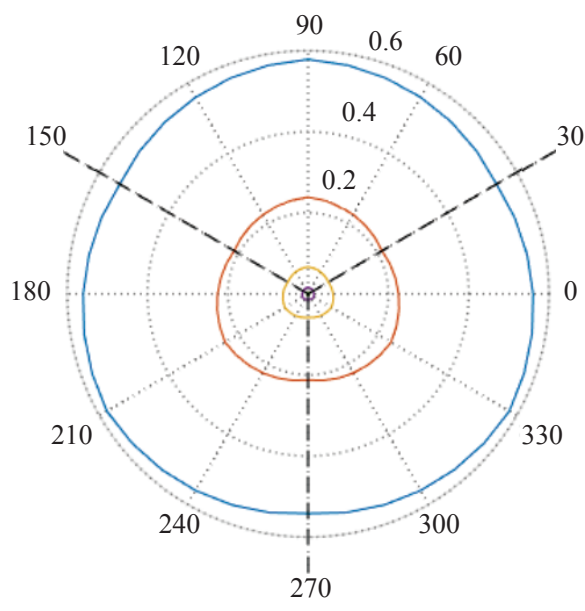

c) $K=200$

Figure 10 - Car trip proportion in homogeneous case
Case 1-6: Spatial impact of heterogeneous parking lots in different supply and demand relations

In this case, more common scenarios with heterogeneous parking lots (different in capacity and parking price) are discussed. One is that the total available parking spots are adequate, as depicted in Figure 11, with the capacity of three parking lots $K_{1}, K_{2}$ and $K_{3}$ that are equal to $200,1,200,1,200$, respectively, and the other is that the total available parking spots of the system are scarce, as depicted in Figure $11 b$, with the capacity of three parking lots $K_{1}, K_{2}$ and $K_{3}$ that are equal to $100,400,400$, respectively. The legend and parameter settings are the same as Case 1-5. By observing two figures, the following conclusions are made:

First, as shown in Figure 11, the advantage area of parking lot 1 is smaller than the other two lots whenever the total spots are adequate or scarce, which illustrates the scarcity of spots which will lead to a relatively high price. But we can also see from the two figures that the maximum mode $\alpha$

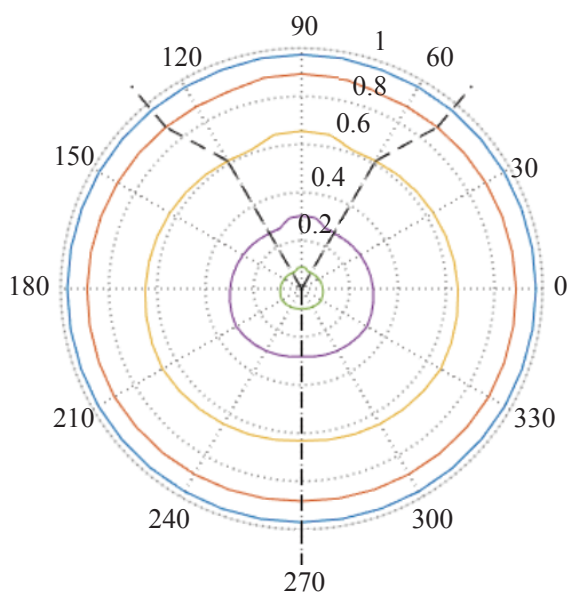

a) $K 1=200, K 2=K 3=1,200$

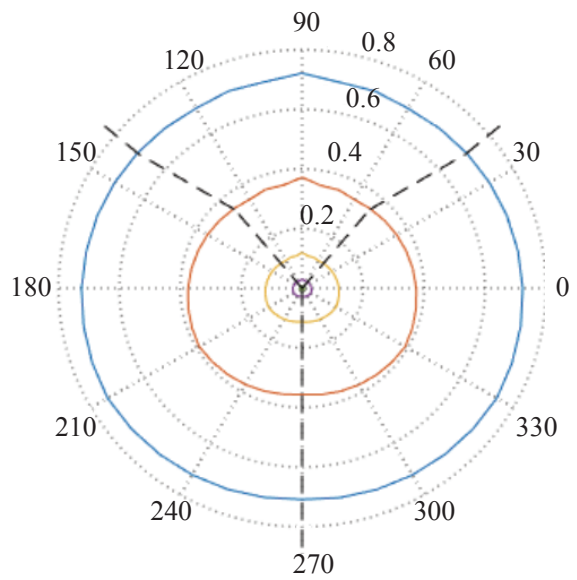

b) $K 1=100, K 2=K 3=400$

Figure 11- Car trip proportion in heterogeneous case 
proportions of each group in three advantage areas are nearly the same, (e.g. origins at $90^{\circ}, 210^{\circ}, 330^{\circ}$ ). It shows that since the spatial distribution of travellers is symmetrical, there is no significant gap in prices. In the scenario of adequate spots (Figure 11a), the parking price of Lot 1 is 20.8 yuan, slightly higher than the price (20.2 yuan) in absolutely sufficient spots scenario depicted by Figure 10a. While in the scarce scenario, the parking price of Lot 1 is 34.6 yuan, 0.5 yuan higher than the prices of other lots. It indicates that the parking price is mainly affected by the overall supply and demand relationship of the parking system. A single lot does not form a monopoly.

Second, in heterogeneous parking lots scenario, different parking prices lead to uneven change in their advantage areas. For example, in Figure 11a, the advantage area of Lot 1 is $60^{\circ}$ to $120^{\circ}$ in groups below $15 \mathrm{~km}$, and it changes to $50^{\circ}$ to $110^{\circ}$ in groups above $20 \mathrm{~km}$. We can see this phenomenon in Figure 11b, as well. In line with Section 4.1, the manager actually achieves the goal of retaining more travellers who live farther through parking prices, because they have a stronger willingness to pay.

Third, as we discussed in the conclusions of Case $1-5$, car trip proportion gets to the maximum value when the origin directly corresponds to the parking lot, and it falls to the minimum value when the angle difference is maximum. Because of the small advantage area, the car trip proportion changes in a small span which leads to convexity in curves around $90^{\circ}$. We can also see from the above figures that the convexity (proportion gap) is significant in groups that have a medium trip length and it gets more "smooth" in the groups which have short or long trip length. The reason is because, first, the travellers with long trip length are not sensitive to price, second, the cardinal number is small for travellers with short trips. In Figure 11a, for example, the proportion gap is $0.5 \%$ in the $25 \mathrm{~km}$ group and $1.4 \%$ in the $5 \mathrm{~km}$ group, but in the groups $10 \mathrm{~km}$ and 15 $\mathrm{km}$, the values are $3.7 \%$ and $4.2 \%$, respectively.

\section{CONCLUSIONS AND PROSPECTS}

This paper uses the day-to-day evolution model to study the interaction between the shared parking supply and demand sides, then discusses the utilization of shared parking mode in the presence of multiple parking lots and trip modes. Shared parking as a complement and potential resource for urban parking, simultaneously benefits the government with a public purpose, the profit-chased manager and the self-concerned travellers. The conclusions obtained in the theoretical analysis and the numerical examples are summarized as follows:

First, when shared parking is in a profitable management scheme, even if the parking demand exceeds the parking supply, there are still some parking spots not used (shown in Case 1-2). Moreover, this phenomenon becomes more obvious as the supply and demand relationship relaxes. The number of actually used parking spots no longer increases after the number of available spots reaches a certain threshold.

Second, the price of shared parking lots is affected by the overall relationship between supply and demand. The scarcity of several parking spots in the area will not result in a substantial increase in the parking price, and the profitable management scheme will not form a monopoly on shared parking under the competition of other trip modes and parking lots.

Third, the manager optimally matches the shared parking lots and the parking demand through allocating parking permits (or rights). With price adjustments, the system quickly converges to the vicinity of the equilibrium point and eventually reaches equilibrium. Case 1-4 shows that the system has higher efficiency when the parking fees are set separately for each lot.

The shared parking issue studied in this paper is an optimization problem for a parking manager and a user equilibrium problem for the travellers. Since demand is a monotonically decreasing function of trip cost, the equilibrium point of the system is unique, but the solution (e.g. parking distribution) is not unique. A day-to-day evolution model is often used in computing system attracting domain, judging convergence, etc. This paper applies the model to describe the interaction process between the manager and the traveller because the mechanism of action of the two is probably a "black box" in practice (e.g. some control measures make it hard to express and calculate in an analytical way). The model has a good performance on the evolution of the mechanism of non-analytic expression.

The more stable public transportation is taken as the alternative mode for the traveller, except for shared parking. The trip cost is expressed by function $f_{l}\left(\rho_{i}\right)+g_{l}$ (e.g. $f$ is often related to the speed and $g$ is often related to the charge). This function is also appropriate to the shared parking mode in this paper. The trip outside parking area $A$ can be regarded 
as the distance-relevant item, while the trip within $A$ is the distance-irrelevant item. Two factors together affect the sharing rate (or competitiveness in the spatial range) of the trip mode. In addition. the larger the value $d f_{l}(\cdot) / d \rho$ is, the weaker the attraction to travellers at farther origins (As Case 1-6 shows, the boundary of the advantage area is bent at a distant location).

Based on the above conclusions, future research on shared parking can be deepened from the following aspects:

The first is the regional unified pricing versus independent market pricing. In practice, many cities adopt the former scheme, some areas being priced lower than the market (or free). According to the user equilibrium principle, the traveller chooses the trip mode with lower-cost travel and reaches the equilibrium point. Low parking prices do not equal lower trip costs, but other deadweight losses (e.g. cruising, queueing) become a complement part during a trip. Additionally, if the demand distribution is imbalanced (Case 1-4), regional pricing will suppress some general demand and cause a waste of resources at the same time. The independent market pricing principle and the adjusting mechanism should be studied further.

The second is public parking versus shared parking. The increase in parking supply alleviates the parking difficulties to a certain extent. However, with the gradual development of shared parking and the increasing number of parking spots, the parking utilization rate may decrease and eventually result in leaving the newly added parking spaces unused at all. From this point, further research should be directed to making full use of the shared parking resources. For instance, compare shared parking with public parking in the aspect of advantage area; if they are similar, the authorities can reduce the public parking supply and promote the shared parking mode. In this way, more urban land will be released.

The third is dynamic pricing versus parking permit scheme. The manager can adjust the number, location, and price of parking easily and accurately through permits (e.g. the permit scheme in this paper). Moreover, when the demand is disturbed (both by routine or stochastically, such as the first few days of the strategy adjustment at each stage or other), the parking permit scheme gives priority to ensuring optimal travel and parking, then balances supply and demand through price. While the traditional charging is often hysteresis and inaccuracy when the actual demand is of uncertainty and fluctuations. Some cities have to adopt a second-optimal option of increasing the charging price and keeping some spots vacant to prevent the possible excess demand. Further, the private property makes shared parking spot more suitable for permit scheme (need to be rented in and out). Future studies can explore new schemes with more convenience and effectiveness based on traditional management schemes.

The fourth is car versus public transit. As discussed before, different modes play their own advantages in certain fields, e.g. cars can take advantage of the speed and time-saving in the areas with better traffic conditions, such as in city periphery, while public transit is less affected by congestion in the city centre and with a low monetary cost. Therefore, bid-rent curves exist between the modes of auto-based and public transit-based. From the perspective of efficiency enhancement, not only developing the modes in their advantage scope is system cost-saving, "retreating" the modes which are not in their advantage scope to the "curve" and pay more attention to them can also reduce system cost (e.g. parking facilities of $P \& R$ can be moved inward if a car can save more time in part of the rest of the journey.)

\section{ACKNOWLEDGEMENTS}

The work presented in this paper was supported by the National Natural Science Foundation of China (91846202, 71771018, 71890972/71890970) and the Science and Technology Foundation of Beijing Jiaotong University(2016RC012).

许铎, 博士研究生 ${ }^{1}$.

电子邮箱: 516472407@qq.com

孙会君, 博士 ${ }^{1}$.

(通讯作者)

电子邮箱: hjsun1@bjtu.edu.cn

1 综合交通运输大数据应用技术交通运输行业重点实验

室（北京交通大学）

中国北京市海淀区上园村 3 号

\section{基于逐日演化模型的赢利性共享停车管理研究}

摘要: 城市停车难日益凸显。然而, 停车供给 并非真正缺乏而是未完全利用。城市居民区私有停 车位数量巨大, 具有共享潜力。由于私有性, 共享 停车管理常具有赢利性。本文使用逐日演化模型研 究共享停车的使用及其对早间通勤的影响。停车供 求双方分别为决定共享停车位经营规模及定价的逐 利管理者, 及对出行成本敏感且可选择多种出行 方式的通勤者。通过分析双方行为及策略, 本文 研究: 1. 出行方式及停车设施对通勤者的吸引, 及 
它们间的竞争，2.停车设施使用率及人员构成。通 过分析两个算例, 本文得出: 1.管理者通过定价及 数量控制即可实现自身收益最大及停车位最优分 配，2.当停车需求高于特定阈值时，共享停车公共 性（系统成本最小）及赢利性（管理者收益最大） 存在一致性, 3.无论供给多寡，处于竞争中的所有 停车设施不会形成垄断。

关键词：共享停车；停车许可；停车位分配； 赢利性管理

\section{REFERENCES}

[1] Litman T. Parking Management Comprehensive Implementation Guide. Victoria, BC: Victoria Transport Policy Institute; 2011.

[2] Axhausen K, Polak J, Boltze M, Puzicha J. Effectiveness of the Parking Guidance Information System in Frankfurt am Main. Traffic Energy \& Control. 1994;35(5): 304-309.

[3] Arnott R, Rowse J. Modeling Parking. Journal of Urban Economics. 1999;45: 97-124.

[4] Vuchic VR. Transportation for Livable Cities. New York, NY: Routledge; 1999.

[5] Shoup D. Cruising for Parking. Transportation Policy. 2006; 13: 479-486.

[6] Ayala D, Wolfson O, Xu B, Dasgupta B, Lin J. Parking slot assignment games. GIS '11 Proceedings of the $19^{\text {th }}$ ACM SIGSPATIAL International Conference on Advances in Geographic Information Systems, 1-4, November 2011, Illinois, USA. ACM SIGSPATIAL GIS; 2011.p. 299-308.

[7] Shoup D. Free Parking or Free Markets. ACCESS Magazine. 2011;1(38): 28-35.

[8] Beijing Transport Institute. 2018 Annual Reports of Transportation Development in Beijing (in Chinese); 2018. Available from: http://www.bjtrc.org.cn/List/in$\mathrm{dex} / \mathrm{cid} / 7 . \mathrm{html}$

[9] Stephen C. Price volatility high for Hong Kong parking spaces available. SCMP (South China Morning Post); 2015. Available from: http://www.scmp.com/ property/hong-kong-china/article/1815118/price volatility-high-hong-kong-parking-spaces

[10] Inci E, Lindsey CR. Garage and Curbside Parking Competition with Search Congestion. Regional Science and Urban Economics. 2015;54: 49-59.

[11] Qian Z, Xiao F, Zhang HM. Managing morning commute traffic with parking. Transp. Res. Part B. 2012;46(7): 894-916.

[12] Qian Z, Rajagopal R. Optimal dynamic parking pricing for morning commute considering expected cruising time. Transp. Res. Part C. 2014;48: 469-490.

[13] Crocker TD. The Structure of Atmospheric Pollution Control System. The Economic of Air Pollution. 1966;61: 81-84.

[14] Dales JH. Pollution, Property, and Prices: An Essay in Policy-Making and Economics. Toronto: University of
Toronto Press; 1968. vii, $111 \mathrm{p}$.

[15] Verhoef E, Nijkamp P, Rietveld P. Tradable Permits: Their Potential in the Regulation of Road Transport Externalities. Environment and Planning B: Planning and Design. 1997;24(4): 527-548.

[16] Yang H, Wang XL. Managing network mobility with tradable credits. Transportation Research Part B. 2011;45(3): 580-594.

[17] Zhang XN, Yang H, Huang HJ. Improving Travel Efficiency by Parking Permits Distribution and Trading. Transportation Research Part B. 2011;45(7): 1018-1034.

[18] Liu W, Yang H, Yin Y, Zhang F. A Novel Permit Scheme for Managing Parking Competition and Bottleneck Congestion. Transportation Research Part C. 2014;44: 265 281.

[19] Liu W, Yang H, Yin Y. Expiable Parking Reservations for Managing Morning Commute with Parking Space Constraints. Transportation Research Part C. 2014;44: 185-201.

[20] Akamatsu T, Wada K. Tradable Network Permits: A New Scheme for the Most Efficient Use of Network Capacity. Transportation Research Part C. 2017;79: 178-195.

[21] Wang J, Zhang XN, Zhang HM. Parking permits management and optimal parking supply considering traffic emission cost. Transp. Res. Part D. 2018;60: 92-103.

[22] Wang J, Zhang XN, Wang H, Zhang M. Optimal parking supply in bi-modal transportation network considering transit scale economies. Transp. Res. Part E. 2019;130: 207-229.

[23] Wang J, Wang H, Zhang XN. A hybrid management scheme with parking pricing and parking permit for a many-to-one park and ride network. Transp. Res. Part $C$. 2020;112: 153-179.

[24] Shao CY, Yang H, Zhang Y, Ke JT. A simple reservation and allocation model of shared parking lots. Transp. Res. Part C. 2016;71: 303-312.

[25] Xu M, Grant-Muller S. Tradable Credits Scheme on Urban Travel Demand: A Linear Expenditure System Approach and Simulation in Beijing. Transp. Res. Procedia. 2017;25: 2934-2948.

[26] Xiao HH, Xu M, Gao ZY. Shared parking problem: A novel truthful double auction mechanism approach. Transp. Res. Part B. 2018;109: 40-69.

[27] Xiao HH, Xu M, Yang H. Pricing strategies for shared parking management with double auction approach: Differential price vs. uniform price. Transp. Res. Part E. 2020;136: 101899 .

[28] Zhang C, Chen J, Li Z, Wu Y. Predicting owners' willingness to share private residential parking spots. Transp. Res. Rec. 2018;2672: 930-941.

[29] Liang JK, Eccarius T, Lu CC. Investigating factors that affect the intention to use shared parking: A case study of Taipei City. Transp. Res. Part A. 2019;130: 799-812.

[30] Ding H. Analyzing and modeling on-street parking choice behavior. MSc thesis. Beijing, CHN: Beijing Institute of Technology; 2016. 